\title{
Testosterone Therapy Improves the First Year Height Velocity in Adolescent Boys with Constitutional Delay of Growth and Puberty
}

\author{
Dinesh Giri, ${ }^{1}$ Prashant Patil, Joanne Blair, ${ }^{1}$ Poonam Dharmaraj, ${ }^{1}$ Renuka Ramakrishnan, ${ }^{1}$ Urmi Das, \\ Mohammed Didi, ${ }^{1}$ and Senthil Senniappan ${ }^{1,}$ \\ ${ }^{1}$ Department of Paediatric Endocrinology, Alder Hey Children's Hospital, Liverpool, United Kingdom \\ "Corresponding author: Senthil Senniappan, Consultant Paediatric Endocrinologist, Department of Paediatric Endocrinology, Alder Hey Children's Hospital NHS Trust, \\ Liverpool, United Kingdom. Tel: +44-1512525281, Fax: +44-1512824606, E-mail: senthilkss@yahoo.co.uk
}

Received 2016 September 15; Revised 2017 January 25; Accepted 2017 February 20.

\begin{abstract}
Background: Constitutional delay of growth and puberty (CDGP) can cause significant psychological distress in adolescent boys. Although testosterone usage in this group has not been shown to affect the final adult height, the effect on the first year height velocity has not been widely reported.

Objectives: The aim is to determine whether testosterone treatment improves the first year height velocity in boys with CDGP when compared to boys with CDGP who go through puberty spontaneously

Methods: Retrospective data from 23 adolescent boys with CDGP was analysed. Ten out of 23 boys (43\%) received testosterone injection (testosterone enanthate, $125 \mathrm{mg}$ ), once every 6 weeks for 3 doses in total. Both the groups (treated and untreated) had their height, bone age and testicular volume measured at the baseline, The height velocity and final predicted adult height were compared at the end of one year between both the groups.

Results: In the testosterone-untreated group, the mean ( \pm SD) chronological age, bone age, height standard deviation scores (SDS) and testicular volume were 14.3 years $( \pm 0.3), 12.1$ years $( \pm 1.6),-1.9( \pm 0.8)$ and $4.7 \mathrm{~mL}( \pm 1.1)$ respectively. Within the testosteronetreated group the mean $( \pm S D)$ chronological age, bone age, height SDS and testicular volume at presentation were 14.4 years $( \pm$ $0.4), 11$ years ( \pm 1.6$),-2.1 \mathrm{SD}( \pm 0.6)$ and $4.5 \mathrm{~mL}( \pm 1.2)$ respectively. The mean age of treatment with testosterone was 14.4 years $( \pm$ $0.44)$. The mean height velocity one year after treatment was $8.4 \mathrm{~cm} /$ year $( \pm 1.7)$ in the testosterone treated group when compared to $6.1 \mathrm{~cm} /$ year $( \pm 2.1)$ in the patients who did not receive treatment $(\mathrm{P}=0.01)$. There was no significant difference in the final predicted height between the 2 groups $(\mathrm{P}=0.15)$.

Conclusions: Testosterone therapy improves the first year height velocity in boys with CDGP, without influencing their final predicted height.
\end{abstract}

Keywords: Testosterone, Constitutional Delay, Delayed Puberty

\section{Background}

Constitutional delay of growth and puberty (CDGP) is a disorder occurring in healthy adolescents and is characterised by slowing of the childhood growth phase, delay in bone maturation and delayed pubertal growth spurt. CDGP is more common in boys than in girls (1). CDGP is a state of temporary hypogonadotropic hypogonadism $(\mathrm{HH})$, which is diagnosed after careful evaluation and excluding any other potential underlying cause of $\mathrm{HH}$.

Differentiating CDGP from other causes of HH can often be challenging. In adolescent boys with CDGP, since the final adult height prognosis is usually within the mid parental centiles, many clinicians prefer to adopt a "wait and watch" approach after sufficiently reassuring patients and families (1). Spontaneous onset of puberty in these patients is often variable and the average duration of pubertal delay is around 3 years (2).
The short stature and delayed puberty can contribute to significant anxiety and distress in adolescent boys, especially when compared to their peers. The psychological distress can be extreme and may interfere with educational and social attainments $(2,3)$. The most common reason for treating patients with CDGP has been the psychological stress experienced by the child and the family (3).

Although the height prognosis is usually good in many of these patients, there is a shorter time interval between the attainment of puberty and pubertal growth spurt when compared to normal children, which can sometimes compromise on the final adult height (2). In $40 \%$ of short children (height $<3$ centile for age and gender), familial short stature and CDGP co-exist $(4,5)$.

Evidence from literature, supporting the use of testosterone and anabolic steroids such as oxandralone without affecting the final adult height, has encouraged the clin- 
icians to use testosterone in boys with CDGP who experience anxiety and distress owing to their height and pubertal delay (6). There is paucity of data reporting the effect of testosterone on the first year height velocity in boys with CDGP.

\section{Objectives}

To determine whether testosterone treatment improves the first year height velocity in boys with CDGP when compared to boys with CDGP who go through puberty spontaneously

\section{Methods}

\subsection{Study Population}

All boys that were referred to the endocrinology clinic between the period 2013 - 2015 with a diagnosis of delayed puberty were identified retrospectively from the hospital medical records and included in the study; 35 adolescent boys were referred to our service for the assessment of delayed puberty and 12/35 adolescent boys were excluded as they had an underlying pathology (inflammatory bowel disease (2), Type I Diabetes (5), congenital hypopituitarism (1), chronic asthma on corticosteroid treatment (2), Klinefelter's syndrome (1) and Noonan's syndrome (1)) We studied the remaining 23 adolescent boys with delayed puberty. CDGP was defined as the temporary growth and pubertal delay in otherwise healthy boys. The diagnosis of CDGP was made after careful clinical assessment and exclusion of any potential underlying pathology or chronic disease by appropriate investigations. Patients with growth or pubertal delay secondary to chronic diseases or corticosteroid treatment were excluded. An informed consent was obtained from the all participants involved in the study. Treatment with testosterone (testosterone enanthate $125 \mathrm{mg}$, every six weeks for three doses) was administered by deep intramuscular injection, to those patients who experienced psychological distress and anxiety associated with short stature and delayed puberty.

\subsection{Measurements}

Baseline investigations were performed in all patients including full blood count, ESR, CRP, renal, liver and bone profile and screening for coeliac disease. The evaluation of baseline pituitary function included analysis of T4, TSH, cortisol and prolactin concentrations.

Anthropometric assessments were performed during clinic visits at 4 monthly intervals by trained nurses using standard techniques (7). Pubertal status was defined according to Tanner's standards (8). Prader Orchidometer was used to estimate the testicular volume (9). The total length of follow up for these patients was 12 months at which point their first year height velocity was calculated to include in the study. Bone age was assessed by TannerWhitehouse 2 method (10). All the participants had their base line bone age measured at the time when the diagnosis of CDGP was made. Adult height predictions were made by the automated BoneXpert adult height predictor software (11), validated for our own population and height for bone age standard deviation score (SDS) using the data for normal British children $(10,12)$.

\subsection{Statistics}

The statistical analyses were performed with SAS software, version 9.3 (SAS Institute Inc., Cary, NC, USA). MannWhitney U-test was used to compare the height velocity between the boys who received testosterone injection and those who did not and proceeded through spontaneous onset of puberty. The results were expressed as mean \pm SD. A P value of less than 0.05 was considered as statistically significant.

\section{Results}

The auxological and anthropometrical parameters of the two groups are shown in Table 1. The mean chronological age at the time of presentation to the endocrine clinic in both the groups was 13.8 years $( \pm 1.6)$. None of the boys had any underlying medical condition. The baseline investigations (full blood count, ESR, CRP, liver function, coeliac screen, renal and bone profile) to look for any evidence of chronic illness were normal. All patients had normal serum concentrations of thyroid, cortisol, IGF1 and prolactin. The mean bone age estimated by the TannerWhitehouse 2 (TW2) method in both the groups was 11.6 years $( \pm 1.7)$ at the time of presentation with a baseline mean height SDS of -2.0 ( \pm 0.7 ).

The baseline auxological parameters (age, height, bone age) and testicular volume were almost similar in both the groups. Ten out of the 23 adolescent boys (43\%) received treatment with testosterone. The mean first year height velocity in the treated group, 12 months after their initial presentation was $8.4 \mathrm{~cm} /$ year $( \pm 1.7$ ) when compared to 6.1 $\mathrm{cm} /$ year $( \pm 2.1)$ in the patients who did not receive treatment $(\mathrm{P}=0.01)$. The mean testicular volume $( \pm S D)$ in the treated and untreated groups at 12 months of follow-up were $7.6 \mathrm{~mL}( \pm 1.5)$ and $5.9 \mathrm{~mL}( \pm 1.4)$ respectively $(\mathrm{P}=0.01)$. There was no difference in the predicted height SDS at the end of their follow-up between the treated group -0.8 ( \pm 1.1) and the group that went into spontaneous puberty -0.9 
Table 1. Auxological and Anthropometrical Parameters Between the Testosterone Treated and Untreated Groups ${ }^{\mathrm{a}}$

\begin{tabular}{|c|c|c|c|}
\hline Variables & Treatment with Testosterone & No Treatment & P Value \\
\hline Chronological age at presentation, $y$ & $14.4 \pm 0.4$ & $14.3 \pm 0.3$ & 0.53 \\
\hline Height SD Score & $-2.1 \pm 0.6$ & $-1.9 \pm 0.8$ & 0.57 \\
\hline Bone age, $y$ & $11 \pm 1.6$ & $12.1 \pm 1.6$ & 0.13 \\
\hline Testicular volume, $\mathbf{m L}$ & $4.5 \pm 1.2$ & $4.7 \pm 1.1$ & 0.6 \\
\hline Testicular volume at the end of 12 months, mL & $7.6 \pm 1.5$ & $5.9 \pm 1.4$ & 0.01 \\
\hline Height velocity at 12 months of follow-up, cm/year & $8.4 \pm 1.7$ & $6.1 \pm 2.1$ & 0.01 \\
\hline Predicted adult height at 12 months of follow-up, cm & $164.26 \pm 3.7$ & $167.44 \pm 6.0$ & 0.15 \\
\hline Predicted adult height SD score & $-0.8 \pm 1.1$ & $-0.9 \pm 0.7$ & 0.86 \\
\hline
\end{tabular}

${ }^{\mathrm{a}}$ Values are expressed as mean $\pm \mathrm{SD}$.

$( \pm 0.7)(\mathrm{P}=0.86)$. No adverse effect from the administration of testosterone injections was reported.

\section{Discussion}

CDGP, a state of transient hypogonadism and delayed bone maturation occurring in healthy adolescent boys, is often managed by explaining the diagnosis and offering adequate reassurance to the patient and the family. A family history of delayed puberty is often present. In a proportion of adolescent boys, the short stature and delayed puberty can cause low self-esteem, reluctance to participate in athletic activities, social isolation and impaired academic performance, imposing a major psychological stress on the patient and the family (2). A small percentage of the adolescent boys with CDGP may not attain their predicted adult height, as the time duration after the onset of spontaneous puberty until the pubertal growth spurt is shorter than in normal children and the peak growth velocity is attenuated (2). These factors, especially the psychological distress and anxiety experienced by the patient and families have driven the clinicians towards treating this condition.

Various medications, including testosterone (13), anabolic steroids (14), and growth hormone (15), have been used to treat CDGP. Growth hormone treatment in CDGP is not appropriate, as these patients do not have an organic GH deficiency (16). Testosterone and anabolic steroids have been used successfully in the treatment of CDGP. There has been some anxiety that androgen therapy can be associated with an inappropriate advance in skeletal maturation compromising the final adult height (17).

More recent studies and randomised control trials have shown that the use of testosterone in CDGP does not affect the final adult height. Most clinicians, who consider treatment, wait until a chronological age of 14 years and a bone age of 12 years. A short course low-dose depot of intramuscular testosterone has been shown to be a welltolerated and effective therapy (18). The aim of the above therapeutic interventions has been to bring forward the growth spurt without a decrease in height potential. A comprehensive review by Soliman et al, highlights the importance of testosterone therapy in boys with CDGP. The authors argue that a good percentage of untreated boys with CDGP end up being short for the general population. There have been concerns that the state of hypogonadism, although transient can affect the bone mineral content and adult bone mass, although the evidence for this is not conclusive (19).

Our study showed that there is a significant improvement in the first year height velocity in boys with CDGP, treated with a short course of testosterone injections, compared to those not treated. This has an important implication in improving the patient's self-confidence with his peers and plays an important role in the psychological well being of the patient. The patients in the treated group were noted to report an improvement in their self-confidence and quality of life, although a formal quality of life score was not performed in these patients. Our study, similar to previous studies shows that testosterone treatment in CDGP causes growth acceleration without an effect on the predicted final adult height. Despite having the limitation of being a retrospective study design and small cohort of patients, our study has also specifically demonstrated the growth acceleration to be evident from the first year after treatment, an expected but important observation that can have potential positive impacts on the patient and the family.

\subsection{Ethics Approval and Consent to Participate}

According to the guidelines of the ethics committee of Alder Hey Children's NHS foundation trust, this study 
did not require ethics approval since (a) the data collection were performed retrospectively, (b) therapies were not altered and (c) individual patient data are not transferred outside the university. An informed consent was obtained from the patients involved in the study.

\section{Acknowledgments}

The authors would like to thanks the staff nurses of the Endocrine department and the outpatient clinic for their contribution towards patient auxology measurements and administering testosterone injections.

\section{Footnotes}

\section{Conflict of Interests: None.}

Financial Disclosure: Nothing to disclose.

\section{References}

1. Albanese A, Kewley GD, Long A, Pearl KN, Robins DG, Stanhope R. Oral treatment for constitutional delay of growth and puberty in boys: a randomised trial of an anabolic steroid or testosterone undecanoate. Arch Dis Child. 1994;71(4):315-7. doi: 10.1136/adc.71.4.315. [PubMed: 7979523].

2. Soliman AT, De Sanctis V. An approach to constitutional delay of growth and puberty. Indian J Endocrinol Metab. 2012;16(5):698-705. doi: 10.4103/2230-8210.100650. [PubMed: 23087852]

3. Gordon M, Crouthamel C, Post EM, Richman RA. Psychosocial aspects of constitutional short stature: social competence, behavior problems, self-esteem, and family functioning. J Pediatr. 1982;101(3):47780. doi: 10.1016/S0022-3476(82)80093-0. [PubMed: 7108676].

4. Wehkalampi K, Widen E, Laine T, Palotie A, Dunkel L. Patterns of inheritance of constitutional delay of growth and puberty in families of adolescent girls and boys referred to specialist pediatric care.JClin Endocrinol Metab. 2008;93(3):723-8. doi: 10.1210/jc.2007-1786. [PubMed: 18160460].

5. Poyrazoglu S, Gunoz H, Darendeliler F, Saka N, Bundak R, Bas F Constitutional delay of growth and puberty: from presentation to final height. I Pediatr Endocrinol Metab. 2005;18(2):171-9. doi: 10.1515/JPEM.2005.18.2.171. [PubMed: 15751606].
6. Uruena M, Pantsiotou S, Preece MA, Stanhope R. Is testosterone therapy for boys with constitutional delay of growth and puberty associated with impaired final height and suppression of the hypothalamo-pituitary-gonadal axis?. Eur J Pediatr. 1992;151(1):15-8. doi: 10.1007/BF02073882. [PubMed: 1728537].

7. Brook CGD. Growth assessment in childhood and adolescence. Oxford: Blackwell Scientific Publication; 1982.

8. Tanner JM. Growth at adolescence. 2 ed. Oxford: Blackwell Scientific Publications; 1968.

9. Zachmann M, Prader A, Kind HP, Hafliger H, Budliger H. Testicular volume during adolescence. Cross-sectional and longitudinal studies. Helv Paediatr Acta. 1974;29(1):61-72. [PubMed: 4838166].

10. Tanner JM, Whitehouse RH, Takaishi M. Standards from birth to maturity of height, weight, height velocity and weight velocity: British children, 1965. I. Arch Dis Child. 1965;41(220):454-71. doi: 10.1136/adc.41.219.454.

11. Thodberg HH, Jenni OG, Caflisch J, Ranke MB, Martin DD. Prediction of adult height based on automated determination of bone age. $J$ Clin Endocrinol Metab. 2009;94(12):4868-74. doi:10.1210/jc.2009-1429. [PubMed: 19926715].

12. Tanner JM, Whitehouse RH, Takaishi M. Standards from birth to maturity for height, weight, height velocity, and weight velocity: British children, 1965. II. Arch Dis Child. 1966;41(220):613-35. doi: 10.1136/adc.41.220.613. [PubMed: 5927918].

13. Richman RA, Kirsch LR. Testosterone treatment in adolescent boys with constitutional delay in growth and development. $N$ Engl J Med 1988;319(24):1563-7. doi: 10.1056/NEJM198812153192402. [PubMed: 3200264].

14. Marti-Henneberg C, Niirianen AK, Rappaport R. Oxandrolone treatment of constitutional short stature in boys during adolescence: effect on linear growth, bone age, pubic hair, and testicular development. J Pediatr. 1975;86(5):783-8. [PubMed: 1133662].

15. Bierich JR. Treatment by hGH of constitutional delay of growth and adolescence. Acta Paediatr Scand Suppl. 1986;325:71-5. doi:10.1111/j.16512227.1986.tb10368.x. [PubMed: 3296641].

16. Buyukgebiz A, Hindmarsh PC, Brook CG. Treatment of constitutional delay of growth and puberty with oxandrolone compared with growth hormone. Arch Dis Child. 1990;65(4):448-9. doi: 10.1136/adc.65.4.448. [PubMed: 2346341].

17. Dannenhoffer R, Crawford JD. Testosterone need questioned. Pediatrics. 1983;71(4):666-7. [PubMed: 6835747]

18. Albanese A, Stanhope R. Predictive factors in the determination of final height in boys with constitutional delay of growth and puberty. J Pediatr. 1995;126(4):545-50. doi: 10.1016/S0022-3476(95)703470. [PubMed: 7699531].

19. Moreira-Andres MN, Canizo FJ, de la Cruz FJ, Gomez-de la Camara A Hawkins FG. Bone mineral status in prepubertal children with constitutional delay of growth and puberty. EurJEndocrinol. 1998;139(3):2715. doi: 10.1530/eje.0.1390271. [PubMed: 9758435]. 